\title{
KAJIAN STILISTIKA BERFOKUS PADA PENGGUNAAN BAHASA KIAS UNTUK MEMAHAMI PESAN PENGARANG DALAM KUMPULAN PUISI HUJAN BULAN JUNI KARYA SAPARDI DJOKO DAMONO
}

\author{
Irfan Hardian \\ Program Studi Magister Pendidikan Bahasa dan Sastra Indonesia \\ Pascasarjana Universitas Pasundan \\ Surel: hardianirfan@gmail.com
}

\begin{abstract}
Abstrak
Penelitian ini dimaksudkan untuk mengetahui karakteristik kumpulan puisi Hujan Bulan Juni melalui pendeskripsian penggunaan bahasa kias untuk mengetahui pesan pengarang. Penelitian ini menggunakan metode deskriftif-anatiltis, artinya setiap data yang sudah diperoleh kemudian dianalisis. Data kualitatif diperoleh dari hasil kajian terhadap penggunaan bahasa kias, lima belas puisi Hujan Bulan Juni mempunyai karakteristik yang berbeda, secara keseluruhan bahasa kias yang digunakan yaitu perbandingan (metafora dan personifikasi), pertentangan (oksimoron, klimaks, dan litotes), pertautan (sinekdoke dan erostetis), perulangan jenis majas repetisi dan ungkapan namun terdapat bahasa kias yang dominan dipakai oleh penyair yaitu penggunaan bahasa kias jenis personifikasi. Sedangkan pesan pengarang dalam lima belas puisi tersebut berkaitan dengan kehidupan sosial manusia yaitu ada yang bertemakan cinta, kerinduan, kesedihan, hingga yang bertemakan kematian. Selanjutnya berdasarkan hasil kajian penggunaan bahasa kias untuk mengetahui pesan pengarang, pedoman kriteria penggunaan bahan ajar dan pemikiran guru matapelajaran bahasa indonesia, maka kumpulan puisi Hujan Bulan Juni dapat digunakan sebagai materi atau bahan ajar karena mengandung nilai-nilai yang baik berdasarkan hasil analisis.
\end{abstract}

Kata Kunci: Kajian Stilistika, Bahasa Kias, Puisi, Bahan Ajar.

\section{Jurno Abstract \\ Pendidikan Bahasa, Sastra}

This research is intended to find out the characteristics of the collection of Hujan Bulan Juni through the descriptions of the use of kias language to find out the author's message. This study uses descriptive-anatiltis method, meaning that every data that has been obtained then analyzed. Qualitative data obtained from the results of the study of the use of language kias, fifteen poems of Hujan Bulan Juni has different characteristics, the overall kias language used is the comparison (metaphor and personification), contradiction (oximoron, climax, and litotes), linkage (sinekdoke and Erostetis), repetition type repetition and expression but there is a dominant kias language used by the poet that is the use of language kias personification type. While the author's message in fifteen poems is related to human social life that there is a theme of love, longing, sadness, to the death-themed. Furthermore, based on the 
results of the study of the use of kias language to find out the author's message, the guidance of the use of teaching materials and teacher thinking in Indonesian language, then the collection of Hujan Bulan Juni can be used as material or teaching materials because it contains good values based on the analysis.

Keywords: Stylistic Studies, figure of speech, Poetry, Teaching Materials.

\section{PENDAHULUAN}

Kajian terhadap teks sastra yang bertujuan untuk memahami karya sastra secara menyeluruh, sekarang ini semakin berkembang dengan berbagai macam pendekatannya. Secara umum pendekatan tersebut meliputi pendekatan intrinsik dan pendekatan ekstrinsik.

Sudjiman (1993:1) mengatakan, bahwa setiap pengkajian sastra pada dasarnya bertujuan unuk dapat memahami karya sastra dengan lebih baik, dengan begitu manfaat dari karya sastra tersebut dapat dinikmati lebih intens, serta ada manfaat yang dirasakan dalam kehidupan si pembaca. Dengan kata lain semua pendekatan baik instrinsik maupun ekstrinsik, dilakukan sebagai usaha dalam memahami makna yang terkandung dalam karya sastra sehingga karya sastra tersebut dapat dinikmati dan dapat bermanfaat bagi kehidupan.

Pada kajian intrinsik karya sastra, bahasa sebagai medium sastra tidak dapat diabaikan. Karena pada dasarnya karya sastra merupakan bentuk curahan hati penyair yang diejawantahkan kedalam bentuk tulisan yang kemudian kita kenal dengan nama teks sastra atau karya sastra. Dalam hal ini Sudjiman (1993:2) mengatakan, bahwa pengkajian karya sastra dari segi bahasa dan gaya bahasa biasa disebut dengan pengkajian stilistik.

Bahasa kias merupakan salah satu unsur yang tidak bisa dilepaskan dalam karya sastra, khususnya puisi. Karena pada dasarnya bahasa puisi merupakan metafor. Namun dengan kekhasan puisi yang menggunakan bahasa kias ataupun permajasan, tidak sedikit pembaca atau penikmat sastra tidak menangkap pesan yang hendak disampaikan pengarang, padahal seharusnya sastra mempunyai tujuan berolehnya pengalaman seperti yang ungkapkan Rusyana (1982:6) yang menyatakan, bahwa sastra harus mempunyai tujuan beroleh pengalaman dan pengetahuan tentang sastra.

Proses pengapresiasian sastra sangat berpengaruh untuk tercapainya tujuan dalam sastra karena saat seseorang mengapresiasi sastra maka akan melibatkan tiga aspek sebagaimana diungkapkan Squire dan Taba (Aminuddin, 2013:34) yaitu (1) aspek kognitif, (2) aspek emotif dan (3) aspek evaluatif. Tujuan-tujuan tersebut akan sangat bermanfaat bagi pembaca sastra atau peserta didik, apabila peserta didik mampu mempunyai variasi atau pendekatan dalam menginterpretasi sastra dengan baik.

Pada pembelajaran Bahasa Indonesia di sekolah terdapat materi pembelajaran bersastra, setidaknya ada pembelajaran mengenai puisi, prosa, dan drama. Di antara ketiga jenis karya sastra tersebut, minat baca siswa sebagian besar pada puisi. Dari minat siswa nampaknya puisi bisa dijadikan karya sastra yang disenangi oleh para siswa karena alasan puisi mampu mewakili perasaan dalam tulisan yang padat makna.

Bahasa kias erat hubungannya dengan majas. Oleh karena itu dalam penelitian ini penyusun mempunyai 
gagasan untuk mengetahui bahasa kias yang terdapat dalam puisi dengan menggunakan kajian stilistika pada penggunaan bahasa kias dalam puisi sebagai pemilihan dan pemanfaatan bahan ajar pada jenjang sekolah menengah atas. Hal ini dilakukan karena memang ada asumsi bahwa pembelajaran sastra di sekolah-sekolah kurang berhasil dalam mencapai tujuantujuan pembelajaran yang diharapkan. Pengajaran sastra tampaknya belum mencapai target sesuai hasil yang diharapkan. Hal ini dapat disimpulkan dari banyaknya keluhan, baik tentang jumlah dan mutu pengajar, jumlah dan mutu buku-buku yang dipergunakan, maupun tentang hasil belajar yang belum mencapai hasil yang memuaskan.

Sekaitan dengan permasalahan di atas Aminuddin (1995:65) menyatakan, bahwa karya sastra dapat digunakan sebagai bahan ajar atau materi dalam pengajaran. Berangkat dari pendapat tersebut peneliti tertarik untuk menggunakan karya sastra yang telah dikaji untuk dijadikan media dan bahan untuk pembelajaran di sekolah.

Hal tersebut semata-mata hanya untuk membuat tujuan pembelajaran sastra dapat dilakukan dengan lebih baik lagi. Dengan demikian, pemilihan bahan pembelajaran sangatlah penting bagi seorang pendidik, dan hal itu sudah harus memenuhi kriteria bahan ataupun media yang efektif untuk digunakan dalam proses belajar mengajar.

Uraian di atas, membuat peneliti tertarik untuk mengembangkan permasalahan apresiasi sastra pada siswa menengah atas dengan objek sastra puisi. Hal ini difokuskan dalam penelitian untuk menafsirkan penggunaan gaya bahasa kias dalam karya sastra khususnya "Antologi Puisi Hujan di Bulan Juni Karya Sapardi Djoko
Damono" untuk menambah khazanah sastra dalam hal bahan ajar bahasa Indonesia yang digunakan dalam proses pembelajaran. Sekaitan dengan hal itu, maka peneliti membuat penelitian dengan judul "Kajian Stilistika Berfokus pada Penggunaan Bahasa Kias untuk Memahami Pesan Pengarang dalam Kumpulan Puisi Hujan Bulan Juni Karya Sapardi Djoko Damono".

\section{METODE}

Metode yang digunakan dalam penelitian ini adalah metode deskriptif analisis. Deskriptif adalah suatu bentuk penelitian yang paling dasar ditunjukan untuk mendeskripsikan atau menggambarkan fenomena-fenomena yang ada, baik fenomena yang bersifat alamiah maupun rekayasa manusia.

Melalui metode ini, penulis akan mendeskripsikan penggunaan bahasa kias beserta amanat yang terdapat pada kumpulan puisi Hujan Bulan Juni karya Sapardi Djoko Damono, serta kelayakan kumpulan puisi tersebut untuk dijadikan bahan ajar ajar untuk jenjang Sekolah Menengah Atas.

\section{HASIL DAN PEMBAHASAN}

1. Keterpautan Penggunaan Bahasa Kias dengan Pesan Pengarang

Bahasa kias yang terdapat dalam kumpulan puisi Hujan Bulan Juni diantaranya majas perbandingan, pertentangan, pertautan, dan perulangan. Jenis-jenis bahasa kias tersebut memiliki keterpautan dengan pesan pengarang yang hendak disampaikan.

\section{a. Keterpautan Penggunaan Bahasa kias dengan Pesan Pengarang dalam Kumpulan Puisi Kesatu}

Pada puisi pertama, berdasarkan data yang telah dianalisis, pemunculan bahasa kias jenis metafora lebih sering digunakan. Penggunaan metafora dimak- 
sudkan penyair untuk memberikan gambaran tentang perasaan sedih pengarang dengan cara membandingkan perasaannya dengan hal-hal yang lain seperti pada bait dan larik pertama penyair menggunakan kata "kau" yang kemudian dibandingkan dengan frasa "menjelma langit semalaman" maka dengan adanya metafora tersebut kita mendapatkan pengimajian tentang keaadaan dan perasaan penyair sehingga pesan yang hendak disampaikan bisa kita terima dengan lebih baik.

Selain itu, dalam puisi pertama penyairpun menggunakan bahasa kias jenis personifikasi dan repetisi. Seperti halnya penggunaan metafora, penggunaan personifikasi dan repetisi juga dimaksudkan untuk lebih memberikan gambaran-gambaran tentang perasaan yang ada dalam puisi tersebut.

\section{b. Keterpautan Penggunaan Bahasa kias dengan Pesan Pengarang dalam Kumpulan Puisi Kedua}

Pada puisi kedua, berdasarkan data yang telah dianalisis, terdapat empat jenis bahasa kias, yaitu bahasa kias jenis sinekdoke, metafora, personifikasi, dan oksimoron.

Penggunaan bahasa kias jenis oksimoron dimaksudkan untuk memberikan efek pencitraan yang lebih kuat. Adapun penggunaannya terdapat pada larik "kupandang semesta" yang dimunculkan oleh pengarang dengan maksud penyampaian keluasannya memandang dunia.

Sedangkan penggunaan bahasa kias jenis metafora, personifikasi, dan oksimoron dihadirkan oleh pengarang dengan maksud mengimajikan keadaan yang lebih mendalam tentang keadaan pengarang pada saat itu. Seperti pada penggunaan bahasa kias jenis personifikasi pada larik "daun bertahan pada tangkainya ketika hujan tiba kudengar bumi sedia kala" maksud pengarang hendak menyampaikan kesepiannya yang mendalam hingga dilukiskan seperti daun yang bisa mendengar suara bumi.

\section{c. Keterpautan Penggunaan Bahasa kias dengan Pesan Pengarang dalam Kumpulan Puisi Ketiga}

Penggunaan jenis bahasa kias pada puisi ketiga hanya menggunakan bahasa kias jenis personifikasi saja. pada bait pertama penggunaan bahasa kias jenis personifikasi terdapat pada larik kesatu dengan ditandai oleh kata "jendela" yang dihidupkan oleh kata "menakutkan" hal ini dapat kita tafsirkan bahwa penyair hendak menyampaikan ketakutannya terhadap waktu yang terus berjalan.

Pada bait selanjutnya pengarang kembali mengunakan majas personifikasi dengan cara menghidupkan kata "ia" yang sesungguhnya mengacu kepada "jam" namun disandingkan dengan kata "meminta izin memutar jarum-jarum tua yang tergesa-gesa saja berdetak" layaknya manusia. Bait tersebut dapat ditafsirkan bahwa penyair berusaha menguatkan kembali bait-bait sebelumnya perihal waktu yang tak pernah menunggu.

d. Keterpautan Penggunaan Bahasa kias dengan Pesan Pengarang dalam Kumpulan Puisi Keempat

a dan Doe Bahasa kias yang digunakan pada puisi keempat yaitu bahasa kias jenis metafora dan personifikasi. Penggunaan bahasa kias jenis metafora terlihat lebih dominan daripada personifikasi, bahasa kias personifikasi dapat kita lihat pada bait kesatu pada larik "mantel dan topi" yang dihidupkan dengan sifat insani yaitu kata "tua" Pada bait tersebut penga-rang seolah menyampaikan bahwa usia pengarang sudah 
tidak muda lagi, hal itu digambarkan dengan kata mantel dan topi tua.

Sedangkan, penggunaan bahasa kias jenis metafora Pada bait pertama pengarang seolah menyampaikan bahwa usia pengarang sudah tidak muda lagi, hal itu digambarkan dengan kata" mantel dan topi tua". Sedangkan Kata hutang-hutangku dalam larik tersebut mengacu kepada dosa yang sering dilakukan.

e. Keterpautan Penggunaan Bahasa kias dengan Pesan Pengarang dalam Kumpulan Puisi Kelima

Pada puisi kelima, terdapat tiga jenis bahasa kias yang digunakan pengarang, yaitu bahasa kias jenis erostetis, sinekdoke, dan metafora. Adapun penggunaan bahasa kias jenis erostetis yaitu pada bait kesatu yaitu ditunjukan oleh larik "Kaukah yang menyapaku selamat pagi?" yang sesungguhnya tidak memerlukan jawaban si pembaca. Dalam hal ini Penyair membuka puisinya dengan sebuah renungan tentang kehidupan berupa sapaan yang sejatinya dapat kita peroleh dari seseorang.

Penggunaan bahasa kias jenis sinekdoke yaitu ditunjukan oleh kata "menyihir alam" padahal sesungguhnya bisa jadi hanya sebagian alam saja yang akan di sihir. Larik tersebut dapat bermakna bahwa penyair sedang meratapi kepergian sesuatu yang sangat berharga dan kembali ke asal. Sedangkan penggunaan bahasa kias jenis metafora yaitu ditunjukan oleh larik "matahari, bau busuk kembang, dan suara burung akan menjelma terompet" yang di ibaratkan dengan kata sandingannya. Larik tersebut dapat bermakna bahwa suatu saat akan datang dimana matahari yang mengeluarkan bau busuk (kiamat).

f. Keterpautan Penggunaan Bahasa kias dengan Pesan Pengarang dalam Kumpulan Puisi Keenam

Pada puisi keenam penggunaan bahasa kias jenis personifikasi lebih dominan dibandingkan dengan jenis bahasa kias yang lainnya, hal ini dimaksudkan pengarang untuk lebih mengimajikan puisinya dengan perbandingan-perbandingan hal yang lain. Hal itu dapat kita lihat pada bait kesatu terdapat kata "bumi" yang seolah-olah mempunyai nyawa ditandai dengan kata "tak pernah membeda-bedakan. Seperti ibu yang baik", hal ini dapat kita tafsirkan bahwa keadaan pengarang waktu itu sedang membandingkan bumi dengan seorang ibu, maksudnya semua orang entah itu baik ataupun buruk, tetap saja disayangi oleh ibunya, begitu pula halnya dalam puisi ini seolah pengarang ingin menyampaikan bahwa bumi tidak mempedulikan kita baik-buruk, kaya-miskin, ataupun hitam-putih, semua sama akan diterima oleh bumi ketika orang tersebut meninggal.

Selain itu pada puisi keenam ini terdapat gaya bahasa jenis klimaks, yaitu ditandai dengan kata "raja, jendral, pedagang, klerek-klerek" yang semakin lama semakin mendapat penekanan. Penekanan tersebut dimaksudkan pengarang untuk lebih menguatkan pengimajian pembaca mengenai tingkatan-tingkatan yang ada di masyarakat.

g. Keterpautan Penggunaan Bahasa kias dengan Pesan Pengarang dalam Kumpulan Puisi Ketujuh

Pada puisi ketujuh penyair menggunakan majas metafora dan personifikasi. Adapun penggunaan 
metafora yaitu ditunjukan oleh kata "cinta yang tinggal" kemudian diumpamakan seperti "bunga kertas dan lintasan angka-angka". Bila kita maknai "cinta yang tinggal" dapat diartikan bahwa penyair sedang mengenang masa-mmasa kebersamaan dengan seseorang yang kini sedang dirindukan.

h. Keterpautan Penggunaan Bahasa kias dengan Pesan Pengarang dalam Kumpulan Puisi Kedelapan

Pada puisi kedelapan penyair menggunakan majas erostesis dan personifikasi. Adapun penggunaan majas erostesis yaitu ditunjukan oleh pertanyaan pada bait pertama yaitu ditandai oleh kata "mengapa". Pada bait ini penyair hendak menyampaikan pesan tentang rasa sesal tentang perbuatan yang dilakukan oleh seseorang, sedang ada hal yang harus disegerakan yang ditandai oleh kata "mengapa".

i. Keterpautan Penggunaan Bahasa kias dengan Pesan Pengarang dalam Kumpulan Puisi Kesembilan

Pada puisi kesembilan berdasarkan data hasil analisis menunjukan bahwa penyair hanya menggunakan majas personifikasi saja, hal itu bisa saja dimaksudkan penyair untuk membuat sederhana puisinya, namun tetap tidak membuat puisi tersebut tidk mempunyai untsur estetiknyad

Penggunaan majas personifikasi ditandai oleh penggunaan kata Kata "angin, reda, dan jam mengerdip" dimaksudkan penyair untuk menggambarkan keadaan sekitar pada waktu itu.

j. Keterpautan Penggunaan Bahasa kias dengan Pesan Pengarang dalam Kumpulan Puisi Kesepuluh

Pada puisi kesepuluh, berdasarkan data yang telah dianalisis, terdapat dua jenis bahasa kias, yaitu bahasa kias jenis erostesis dan personifikasi. Penggunaan majas erostesis dimaksudkan pengarang untuk memberikan efek penguatan imaji terhadap pembaca, sehingga ketika membaca larik tersebut pembaca langsung mencari jawaban dengan pengalaman-pengalaman yang telah dirasakan pembaca.

Sedangkan penggunaan majas personifikasi dimaksudkan pengarang untuk lebih memperkuat imaji pembaca, hal ini dapat kita lihat pada kata "dunia" (L.3) dihidupkan oleh penyair bertujuan untuk membuat pembaca kembal merenungi kehidupan yang sudah lama dilalui.

k. Keterpautan Penggunaan Bahasa kias dengan Pesan Pengarang dalam Kumpulan Puisi Kesebelas

Pada puisi kesebelas, berdasarkan data yang telah dianalisis, terdapat dua jenis bahasa kias, yaitu bahasa kias jenis personifikasi dan metafora. Penggunaan kedua majas tersebut dimaksudkan pengarang untuk menghidupkan puisinya. Adapun penggunaan bahasa kias jenis personifikasi yaitu ditunjukan oleh larik kata "langit" yang seolah-olah hidup dan "menua" (L. 1) dan pada penggunaan frasa "sampai habis senja", yang mengiba-ratkan senja mempunyai nyawa dan akan habis. (L. 4). Kata "langit" digambarkan "mепиа" dapat ditafsirkan bahwa penyair sedang menggambarkan keadaan sekitar yang hampir malam.

Sedangkan penggunaan majas metafora digunakan penyair untuk lebih memperindah puisi, tidak hanya memperindah namun untuk menyembunyikan kelugasan makna dari puisi tersebut, hal ini ditandai oleh kata 
"waktu" yang disandingkan de-ngan kata "hampir lengkap". Kata "waktu" yang disandingkan dengan kata "hampir lengkap" menyiratkan bahwa penyair memang sedang menungu-nunggu waktu yang biasanya dinikmati, dalam hal ini bisa saja menunggu senja tiba sampai seja berganti malam.

1. Keterpautan Penggunaan Bahasa kias dengan Pesan Pengarang dalam Kumpulan Puisi Kedua Belas

Pada puisi kedua belas, berdasarkan data yang telah dianalisis, terdapat dua jenis bahasa kias, yaitu bahasa kias jenis personifikasi dan metafora. Penggunaan kedua majas tersebut dimaksudkan pengarang untuk menghidupkan puisinya. Adapun penggunaan majas personifikasi pada puisi tersebut ditandai oleh kata "musim" yang seolah-olah mempunyai nyawa, dengan ditandai oleh kata selanjutnya "berdesik-desik pelan".

Kata "musim" yang seolah digambarkan mempunyai nyawa, dimaksudkan penyair agar puisinya lebih bisa menyampaikan tentang hal yang selalu tidak bisa lekang oleh waktu, seperti musim kemarau yang kemudian berganti menjadi Jmusim penghujan. Sedangkan penggunaan majas metafora ditandai oleh kata "angin" yang diumpa-makan "basah tak ada bermuat debu".

m. Keterpautan Penggunaan Bahasa kias dengan Pesan Pengarang dalam Kumpulan Puisi Ketiga Belas

Pada puisi ketiga belas, berdasarkan data yang telah dianalisis, terdapat empat jenis bahasa kias, yaitu bahasa kias jenis personifikasi, repetisi, ungkapan, dan oksimoron. Pada puisi ketiga belas ini penyair lebih banyak menggunakan jenis bahasa kias, namun bahasa kias jenis personifikasi tetap mendominasi dalam puisi tersebut. Adapun penggunaan majas personifikasi pada puisi ketiga belas dengan ditandai dengan penggunaan kata "senyap seketika" seolah-olah mempunyai nyawa" dapat kita tafsirkan bahwa keadaan penyair pada waktu itu sedang merasakan sesuatu yang kembali dirasa setelah sekian lama.

Sedangkan penggunaan majas oksimoron dimaksudkan pengarang untuk lebih mengimajikan puisinya, dengan adanya majas oksimoron pembaca dipaksa untuk lebih memahami lagi isi dari puisi tersebut. Adapun penggunaan majas oksimoron pada puisi tersebut ditandai oleh penggunaan kata "percakapan" yang diban-dingkan dengan "tanpa kata-kata" bbisa kita artikan sebagai pertemuan yang sudah lama dinantikan sampai kata-kata tak mampu lagi terucap.

n. Keterpautan Penggunaan Bahasa kias dengan Pesan Pengarang dalam Kumpulan Puisi Keempat Belas

Pada puisi keempat belas, berdasarkan data yang telah dianalisis, hanya terdapat satu jenis maja yang digunakan dalam puisinya, yaitu penggunaan majas personifikasi. Namun walaupun hanya menggunakan satu jenis majas tetap saja puisi tersebut terlihat sangat istimewa, dengan tidak begitu saja dapat ditafsirkan dengan cara membaca sekilas.

Adapun penggunaan bahasa kias jenis majas personifikasi terlihat pada bait pertama dan kedua yang 
ditandai oleh penggunaan kata "percakapan" dalam bait ini bukanlah merupakan percakapan yang sesungguhnya, namun hanya sebatas metafora antara penyair dan hatinya yang sedang berbicara tentang suatu hal.

o. Keterpautan Penggunaan Bahasa kias dengan Pesan Pengarang dalam Kumpulan Puisi Kelima Belas

Pada puisi kelima belas, berdasarkan data yang telah dianalisis, terdapat dua jenis bahasa kias, yaitu bahasa kias jenis oksimoron dan personifikasi Penggunaan kedua majas tersebut dimaksudkan pengarang untuk menghidupkan puisinya. Penggunaan majas oksimoron dimaksudkan pengarang utuk membandingkan ataupun menghadirkan kembali ingatan tentang hal-hal yang berlainan di dunia. Hal ini dapat terlihat pada penggunaan kata "rindu-dendam" yang jika kita kaitkan dengan puisi tersebut, maka erat kaitannya dengan pemaknaan pengalaman hidup sangpenyair.

Sedangkan penggunaan majas personifikasi ditandai dengan penggunaan kata "Ia pun terkulai perlahan-lahan dengan indah sekali, tanpa satu keluhan" dapatenkitá maknai setelah mendapatkan pelas jaran hidup, dari rindu-dendam, maka akan tiba saatnya kita akan kembali terkulai tak berdaya, namun karena sudah mendapatkan pelajaran maka kita tidak akan pernah mengeluh dengan ketidakberdayaan itu.

\section{PENUTUP}

\section{Simpulan}

Hasil penelitian yang penulis lakukan secara analitis deskriptif terhadap lima belas puisi dalam kumpulan puisi Hujan Bulan Juni karya Sapardi Djoko Damono , yaitu Dalam Doaku, Dalam Doaku I,Tangan Waktu, Sajak Desember, Di Pemakaman, Tentang Penjaga Kubur Yang Mati, Sementara Kita Saling Berbisik, Saat Sebelum Berangkat, Berjalan Di Belakang Jenazah, Sehabis Mengantar Jenazah, Lanskap, Hujan Turun Sepanjang Jalan, Kita Saksikan, Dalam Sakit, Sonet: Hei! Jangan Kaupatahkan. Adapun pelaksanaan kegiatan penelitian ini diarahkan pada pencapaian tujuan penelitian yang telah dirumuskan sebelumnya.

Berdasarkan hasil penelitian yang telah dilakukan, maka diperoleh simpulan sebagai berikut.

1. Jenis bahasa kias yang terdapat pada lima belas puisi tergolong pada jenis bahasa kias perbandingan (metafora dan personifikasi), pertentangan (oksimoron, klimaks, dan litotes), pertautan (sinekdoke dan erostetis), perulangan jenis majas repetisi dan ungkapan.

2. Pesan pengarang dalam lima belas puisi Hujan Bulan Juni sangat dipengaruhiooleh penggunan ragam bahasalkias, hal itu terlihat pada hasil analisis sebelumnya yang menunjukan bahwa penyair begitu mahir menggunakan bahasa kias dalam tiap puisinya. Adapun pesan pengarang pada lima belas puisi yang telah dianalisis berkaitan dengan kehidupan sosial manusia yaitu ada yang bertemakan cinta, kerinduan, kesedihan, hingga yang bertemakan kematian. Pada tiap puisinya penyair 
dominan menggunakan bahasa kias personifikasi sehingga pesan pengarang bisa tersampaikan dengan gambaran-gambaran untuk memperjelas imaji pembacanya.

3. Berdasarkan pertimbangan kajian stilistika penggunaan bahasa kias untuk memahami pesan pengarang, ke lima belas puisi pada kumpulan puisi Hujan Bulan Juni layak dijadikan bahan ajar mata pelajaran bahasa Indonesia pada siswa SMA.

\section{Saran}

Berkenaan dengan kesimpulankesimpulan yang telah diperoleh di atas, dalam hal ini diajukan beberapa saran yang ditujukan kepada beberapa pihak.

1. Puisi-puisi pada kumpulan puisi Hujan Bulan Juni mempunyai karakteristik dan penggunaan bahasa kias yang baik. Oleh karena itu pembaca akan disuguhkan dengan nikmatnya membaca puisi yang dipadukan dengan bahasa kias yang baik. Hal ini tentunya perlu dipertimbangkan untuk menjadi bahan ajar.

2. Pembelajaran sastra hendaknya mempunyai kreativitas baru dalam upaya memahami isi dari suatu karya sastra dengan tetap memandang unsur-unsur dan nilai-nilai yang terkandung dalam karya sastra!rnal II.

3. Para pengajar bahasa dan sastra Indonesia harus kreatif dalam mengondisikan kelasnya dengan cara memperhatikan wawasan terhadap materi pengajaran sastra melalui penelaahan karya sastra dan terus memantau perkembangan teori sastra sebagai bahan apresiasi dan kajian.

4. Para peneliti ada baiknya kajian dan model pengajaran sastra ini ditindak lanjuti agar dapat mengetahui seberapa besar manfaat kajian ini sebagai cara untuk mencapai tujuan pengajaran sastra.

\section{DAFTAR PUSTAKA}

Aminuddin. (2013). Pengantar Apresiasi Karya Sastra. Bandung: Sinar Baru Algesindo.

Aminuddin. (1995). Stilistika: Pengantar Memahami Bahasa dalam Karya Sastra. Semarang: IKIP Semarang Press.

Chaer, Abdul. (2009). Pengantar Semantik Bahasa Indonesia.

Jakarta: Rineka Cipta.

Depdikbud. (2002). Kamus Besar Bahasa Indonesia. Jakarta: Balai Pustaka.

Djajasudarma, T. Fatimah. (2103). Semantik 2. Bandung: Rineka Aditama.

Keraf, Gorys. 1986. Diksi dan Gaya Bahasa. Jakarta: PT. Gramedia.

Kosasih, E. (2012). Dasar-dasar Keterampilan Bersastra. Bandung: Yrama Widya.

Kridalaksana, Harimurti. (2008). Kamus Linguistik Edisi Keempat. Jakarta: Gramedia.

Lestari, Ika. (2013). Pengembangan Bahan Ajar Berbasis Kompetensi. Padang: Akademia Permata.

Majid, A. (2012). Perencanaan Pembelajaran. Bandung: PT Remaja Rosdakarya.

Mulyasa, E. (2006). Menjadi Guru Profesional Menciptakan Pembelajaran Kreatif dan Menyenangkan. Bandung: Rosda Karya Ofset.

Nurgiyantoro, Burhan. (2014). Stilistika. Yogyakarta: Gadjah Mada University Press. 
Pradopo, Rachmat Djoko. (2002)

Pengkajian Puisi. Yogyakarta:

UGM Press.

Rusyana, Yus. (1982). Metode

Pengajaran Sastra. Bandung:

Gunung Larang.

Sudaryat, Yayat. (2011). Makna

dalam Wacana. Bandung:

Yrama Widya.

Sudjiman, Panuti. (1993). Bunga

Serampai Stilistika. Jakarta:

PT Temprint.

Tarigan, Henry Guntur. (2009)

Pengajaran Gaya bahasa.

Bandung: Angkasa.

Widada, Rh. (2006). Saussure untuk

Sastra. Yogyakarta: Jalasutra. 